\title{
Research on V2G Control Strategy for EV Charge and Discharge Equipment
}

\author{
Mai Zhang, Caihong Zhao, Xiaobo Tang, Li Liu, Lijuan Tan \\ School of Electrical and Automation Engineering, Nanjing Normal University, Nanjing, China \\ Email: zhangmai1988@126.com,61081@njnu.edu.cn, xiaobotang@126.com
}

Received March, 2013

\begin{abstract}
In this paper, the fundamental structure of charge and discharge device of $\mathrm{V} 2 \mathrm{G}$ is analyzed. As for three phase voltage source PWM converter's control, this paper presents that the control strategy of direct power control PWM rectifier is adopted under charging operation and constant power control strategy is used under discharging operation. For bidirectional DC/DC converter control strategy, dual closed-loop control of external voltage loop and internal current loop is put into use. The whole system of charge and discharge device of $\mathrm{V} 2 \mathrm{G}$ is modeled and simulated by using the toolbox of PSCAD/EMTDC. Two-way power energy and information interaction of electric vehicle and power grid has been realized, current harmonic on grid side is decreased, power factor and power quality are improved.
\end{abstract}

Keywords: V2G; PWM; Direct Power Control; Constant Power Control; DC/DC Converter

\section{Introduction}

In recent years, the state has vigorously developed smart grid technology [1], Electric vehicles (Electric Vehicle, EV) technology has gained rapid development in China [2]. With the improvement of battery technology and the charge-discharge cycle life, power battery in the Electric vehicles can be used as a distributed energy storage unit. Electric vehicles are not only as a power system load power consumption but also energy stored in vehicles can be given when the power grid needs, which is V2G technology two-way interaction of electric vehicles and smart grid[3-4]. The essence of $\mathrm{V} 2 \mathrm{G}$ technology is on the basis of the full information interaction for electric vehicles and the power grid, which realizes the two-way flow of energy between the vehicles and the power grid. According to the charging and discharging strategy, meet the needs of the premise of the electric vehicle users traveling, remaining energy participates in load regulation, including grid peak-to-valley regulation, standby power, frequency response, and promote the application of renewable energy access and so on, which can bring in revenue for the grid and electric vehicles users. V2G technology implementation will facilitate a truly seamless integration of electric vehicles and smart grid.

The most widely used electric vehicle battery charge and discharge technology in China currently is non-con-

*Project supported by the Nature Science Foundation of the Jiangsu Higher Education Institutions of China (Grant No.2010111Tsj0113) trolled rectifier and DC/DC chopper. This technology has advantages of good dynamic performance, smaller input ripple on DC side, but there are shortcomings as the high harmonic content on the system side, large size, low power factor and pollution on the grid $[5,6]$. With the development of power electronics technology, the system of the charging and discharging of the DC/DC converter technology has been gradually promoted. The system consists of an isolated DC/DC converter and buck chopper. The drawback is that only the resistance is discharged in the discharge of the battery, energy cannot give back to the power grid, resulting in wasting a lot of energy. This paper uses the three-phase PWM converter and bi-directional DC/DC converter to constitute the V2G two-way charging and discharging device of the electric vehicle. The three-phase voltage-type PWM converter uses the control strategy of direct power control of PWM rectifier under charging operation and control strategy of constant power under discharging operation. For bidirectional DC/DC converter control strategy, dual closed-loop control of external voltage loop and internal current loop is put into use. V2G charge and discharge device using the above control strategies has the follow benefits: Reducing the current harmonics of the grid-side in the charging process, improving the power factor and increasing the working frequency. The electric vehicles as an energy storage system can also make the energy feedback to the grid, so the energy utilization can be further raised, achieving the bi-directional flow of energy [7-9]. 


\section{Basic Structure of V2G Bidirectional Charge and Discharge Device}

Electric vehicle charging and discharging device in this paper mainly consists of the three-phase power connected to the electric vehicle batteries and control loop through a transformer, converter module, filter circuit, and bi-directional DC/DC converter. The basic structure is shown in Figure 1.

Converter module adopts voltage type PWM converter consists of IGBT module for energy exchange between the AC grid and DC bus. Voltage type PWM converter works in rectifying state when charging and battery draws energy from the grid. The converter works in invertering state when discharging and battery feedback power to the grid. V2G bidirectional electric vehicle charging and discharging control circuit includes the voltage of the AC side, the current acquisition circuit, the PWM control circuit, the bidirectional conversion control circuit, the DC voltage, current, temperature and the charge and discharge information acquisition circuit. Control circuit obtains charge and discharge instructions, work mode, parameter setting, real-time capacity, controlled time information through high-end DSP devices. Then control the system of double-loop through a feedback signal according to the specified running mode in the case of no failure and drive converter module unit, completing the control of the battery charge and discharge.

\section{The Control Strategy of Charge and Discharge Device}

\subsection{Control of Voltage PWM Converter}

When electric vehicles are in the state of charge, they are equivalent load. When the three-phase PWM rectifier is in rectifier state, the waveforms of the current and voltage of the controlling network side are sine and with the same phase. The power factor is 1 and the output voltage is stable, using control strategy of direct power control of PWM rectifier. As shown in Figure 2, the directly control system of voltage type rectifier is mainly constituted

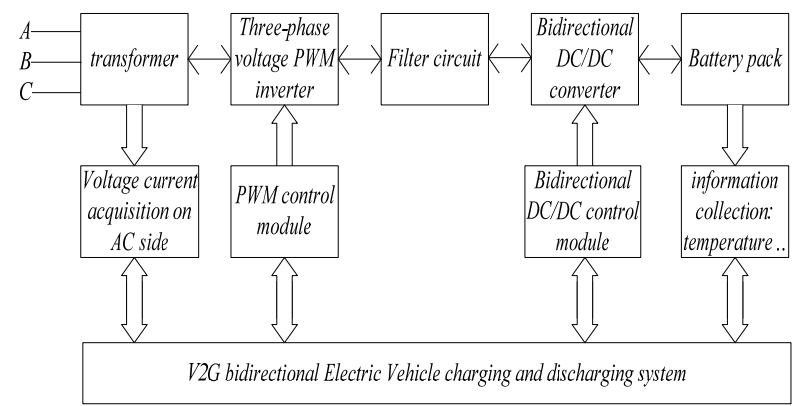

Figure 1. Basic structural diagram of the V2G bidirectional charge and discharge device. by the main circuit and the corresponding control circuit. Rectifier direct power control system uses a dual closedloop control system with DC external voltage loop and internal power loop. The control of DC external voltage loop adopts repetitive control and internal power loop selects the switch quantity through the switch table according to the measured voltage of the voltage side and instantaneous active and reactive power, achieving rectifier of high performance.

Repetitive control is added to the Outer voltage control based on the PI control, the control structure is shown in Figure 3,

The control strategy combining repetitive control and PI control makes the control system have good tracking performance to ensure the control accuracy of system steady state.

Under the circumstances of the same RMS for the AC voltage, internal power loop uses method of direct power control controlling instantaneous active and reactive power of the AC side of the PWM rectifier within a certain range. In order to determine the space vector of power supply voltage, determine the amplitude angle of $\mathrm{u}$ by $u_{\alpha}$ and $u_{\beta}, \theta=\arctan \left(u_{\alpha} / u_{\beta}\right)$. And then determine the interval location of the voltage vector $u$ according to the position of angle $\theta$.

When electric vehicles are in the state of discharge, on the basis of the grid frequency and voltage regulation, using a constant power (PQ) control strategy, the PQ control strategy of the overall block diagram is shown in Figure 4, including the $d q$ conversion, a phase-locked loop (PLL), current control and PWM.

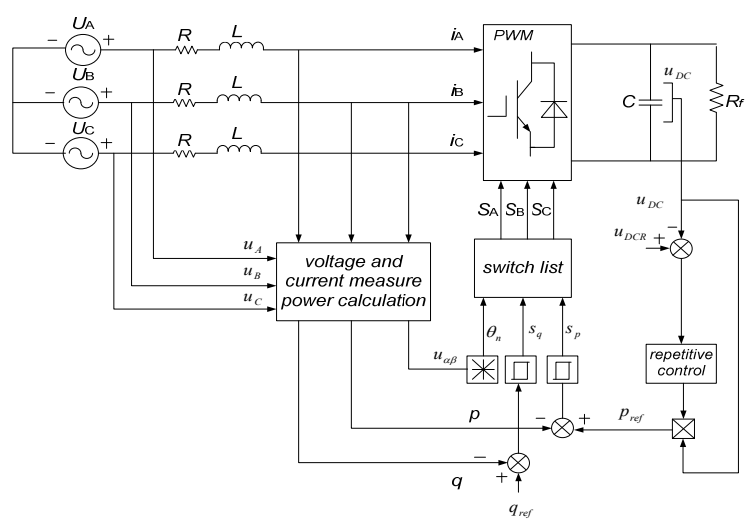

Figure 2. Direct power control system structure.

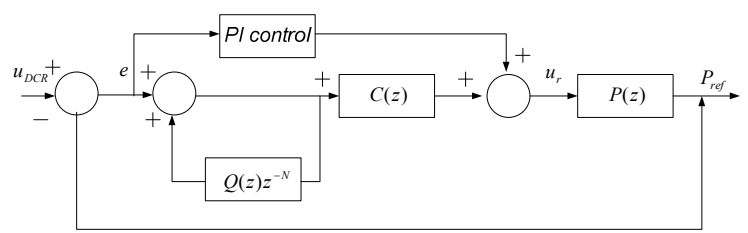

Figure 3. PI control and repetitive control combined control block diagram. 


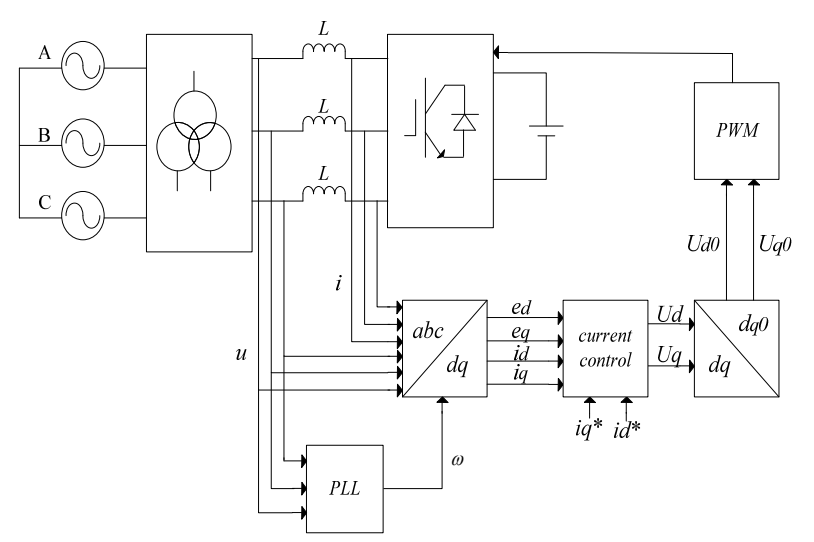

Figure 4. Overall block diagram of PQ control strategy.

Due to the $d, q$-axis variable Coupled with each other, feed forward decoupling control strategy can be used, when the current regulator with PI regulator, the control equation of $u_{d}, u_{q}$ as shown in formula(1) and formula(2)

$$
\begin{aligned}
& u_{d}=-\left(K_{i P}+\frac{K_{i L}}{s}\right)\left(i_{d}^{*}-i_{d}\right)-\omega L i_{q}+e_{d} \\
& u_{q}=-\left(K_{i P}+\frac{K_{i L}}{s}\right)\left(i_{q}^{*}-i_{q}\right)+\omega L i_{d}+e_{q}
\end{aligned}
$$

$K_{i P}$ represents current loop proportional control gain and integral gain; $K_{i L}$ represents integral control gain; $i_{d}{ }^{*}, i_{q}{ }^{*}$ represent $i_{d}, i_{q}$ current command value.

Current loop $d, q$ axis can be controlled independently after decoupling. The output of current loop PI controller and the integration of current state feedback decoupling and grid voltage feed-forward compensation two synthetic AC side of the converter $d, q$-axis output voltage reference value $u_{d}$ and $u_{\mathrm{q}}$, by adjusting the active current $i_{q}$ and reactive current $i_{d}$ to track reference current $i_{q}{ }^{*}$ and $i_{d}{ }^{*}$, and realize respectively control the active power $\mathrm{P}$ and reactive power $\mathrm{Q}$ output. According to formula (3) and (4)

$$
\begin{gathered}
P^{*}=1.5\left(u_{d} i_{d}^{*}+u_{q} i_{q}^{*}\right) \\
Q^{*}=1.5\left(u_{q} i_{d}^{*}-u_{d} i_{q}^{*}\right)
\end{gathered}
$$

Just change the value of $i_{q}{ }^{*}$ and $i_{d}{ }^{*}$, you can adjust the value of active and reactive power, to calculate $\mathrm{P} *$ and $\mathrm{Q}$ *.

\subsection{DC/DC Converter Control}

The charging and discharging of the DC/DC converter usually use half-bridge structure which current can flow in both directions and dual closed-loop control system with external voltage loop and internal current loop. Figures 5 and 6 respectively show a control block diagram for the Buck and Boost mode. The voltage error signal, which is equal to the difference between the ref- erence voltage value and the output voltage value-_Battery side voltage in the Buck mode, and DC-bus side voltage in the Boost mode) obtained from sampling, obtain the reference value of the inductor current in the inner loop (current) control system after going through the voltage PI regulator. The inductor current error value, which is equal to the difference between the reference value of the inductor current as above mentioned and obtained from sampling, obtain the reference value of the Inductor voltage after going through the current PI regulator. Finally, it minus the actual value of the voltage obtained from sampling, and we get the IGBT drive signal by comparing the error and triangle wave.

\section{Simulation Analysis of the System}

To achieve the two-way power energy and information interaction of electric vehicle and power grid, we put the bidirectional DC/DC converter and battery pack with equivalent and model it by using the toolbox of PSCAD/ EMTDC. Main circuit model is shown in Figure 7.

$\mathrm{AC}$ power is $10 \mathrm{kV}$ and we reduce it through the 10 $\mathrm{kV} / 0.4 \mathrm{kV}$ transformer. Transformer uses Dyn11 connection. Inductor filter inductance value is $5 \mathrm{mH}$ and resistance is $0.5 \Omega$ in AC side. Capacitance is $2215 \mu \mathrm{F}$. Simulation time is $0.5 \mathrm{~s}$ and step is $0.2 \mu \mathrm{s}$. Voltage is almost constant in $700 \mathrm{~V}$ in DC side. Voltage waveform is shown in Figure 8, the waveform of the instantaneous value and valid value of current in AC side is shown in Figure 9. We can see that current harmonic on grid side is small from the waveform.

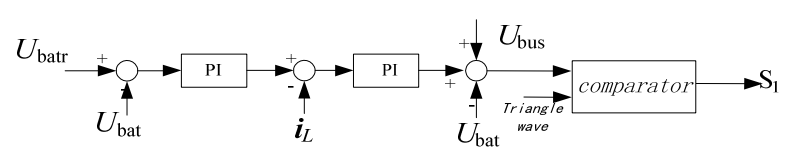

Figure 5 Control block diagram of Buck mode.

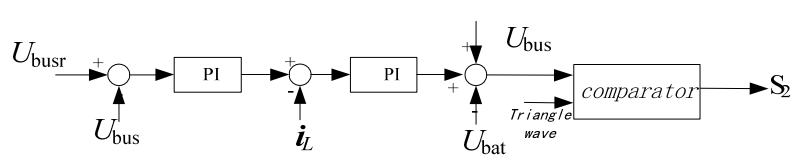

Figure 6 Control block diagram of Boost mode.

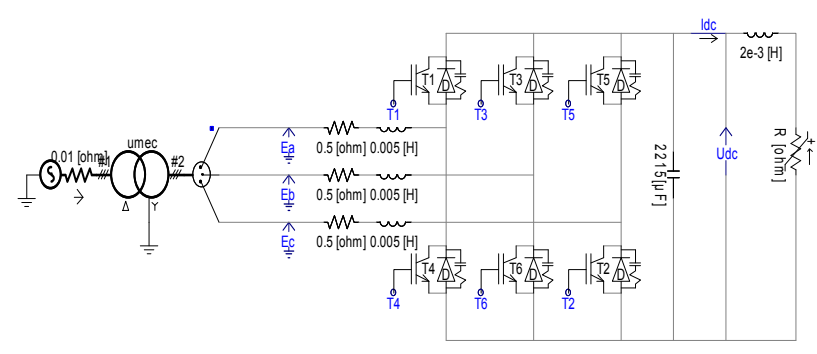

Figure 7. Main circuit model of the charge and discharge device. 
When non-controlled rectifier control is used, the voltage and current waveform of electric vehicles in the state of charging are shown in Figure 10. When direct power control of PWM rectifier is used, A-phase's voltage and current waveforms of electric vehicles in the state of charging are shown in Figure 11.

Figure 11 shows that the system enters rectifier operational status of unity power factor after $0.05 \mathrm{~s}$. The current of AC side is sinusoidal and has the same phase with the voltage with the amplitude about $10 \mathrm{~A}$. By comparing Figure 10 and Figure 11, we can see that the charging voltage and current waveforms has small harmonic under the PWM control mode, almost reaching the standard sine wave.

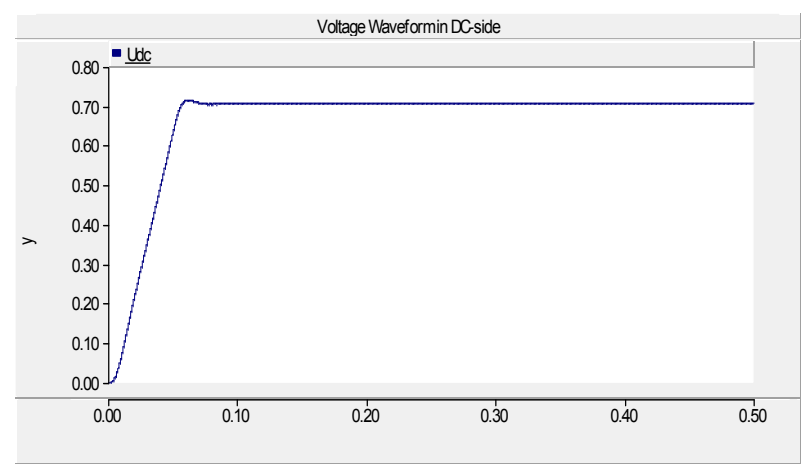

Figure 8 Voltage waveform in DC-side.

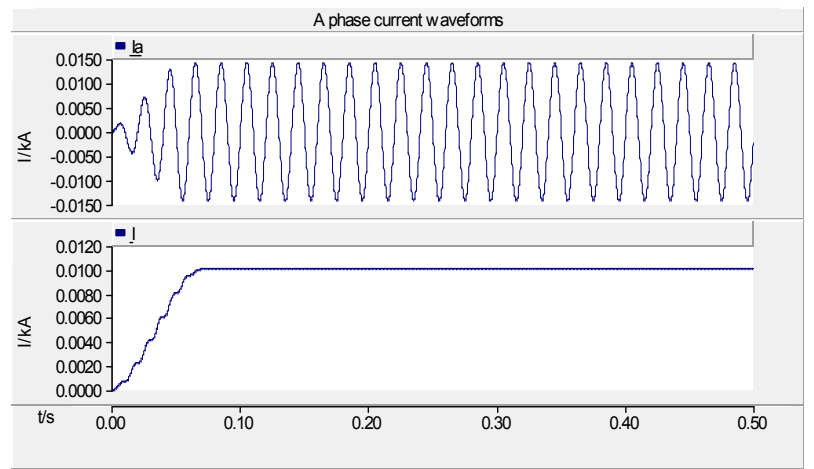

Figure 9. Instantaneous value of the AC side current and RMS waveform.

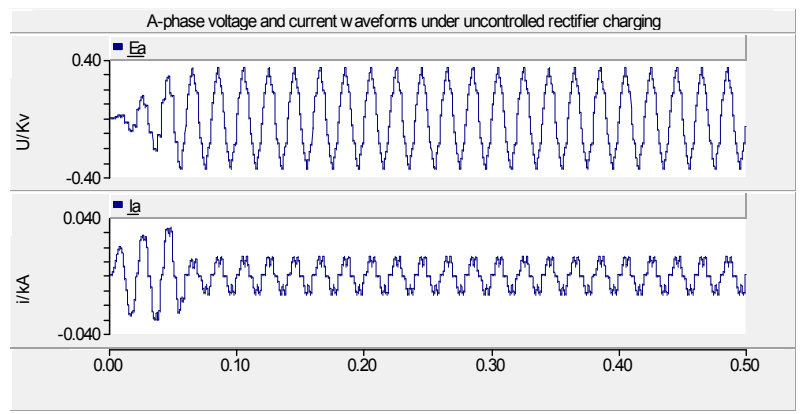

Figure 10. A-phase voltage and current waveforms under uncontrolled rectifier charging.
In order to compare easily, the paper does spectral analysis of line voltage $U \mathrm{ab}$ of the $\mathrm{AC}$ side under the charging state of the non-controlled rectifier and the direct power control of the PWM rectifier respectively. As shown in Figures 12 and 13.

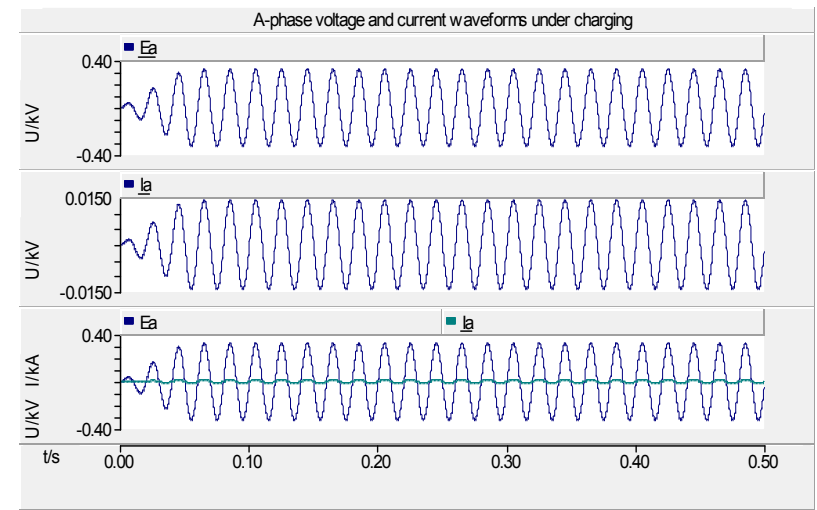

Figure 11. A-phase voltage and current waveforms under charging.

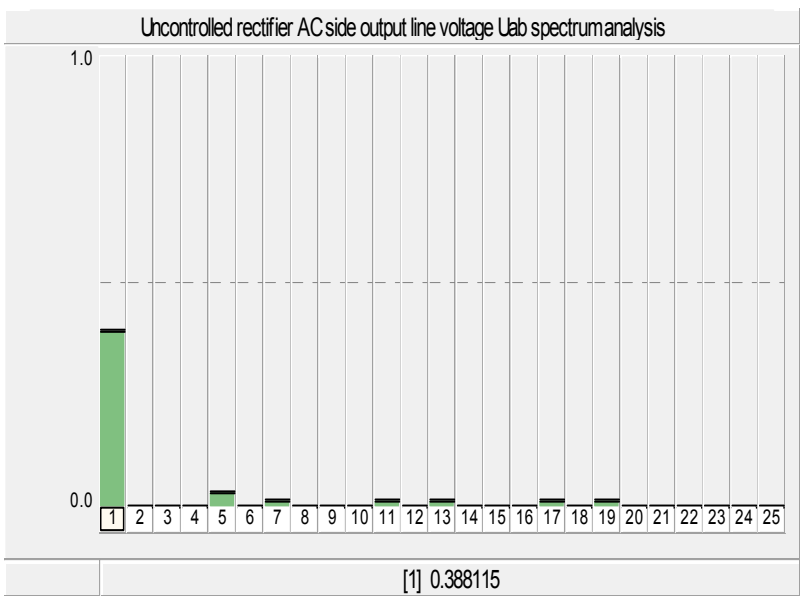

Figure 12. Uncontrolled rectifier AC side output line voltage Uab spectrum analysis.

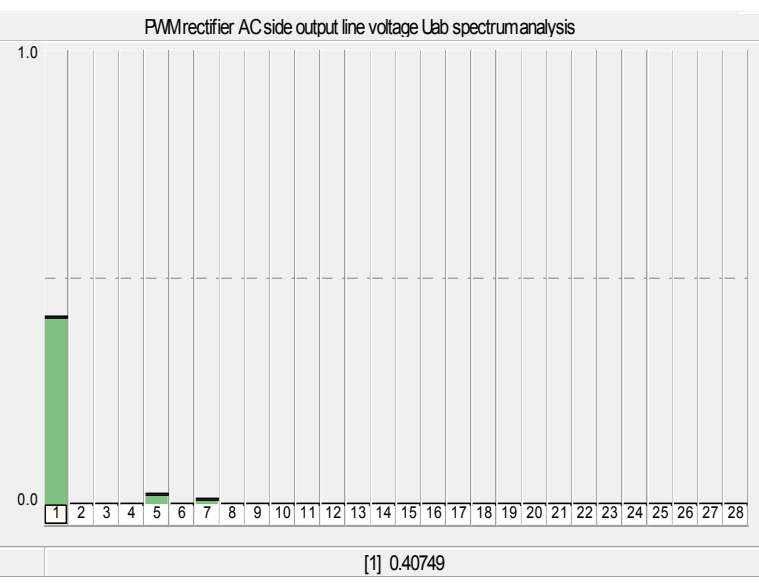

Figure 13. PWM rectifier AC side output line voltage Uab spectrum analysis. 


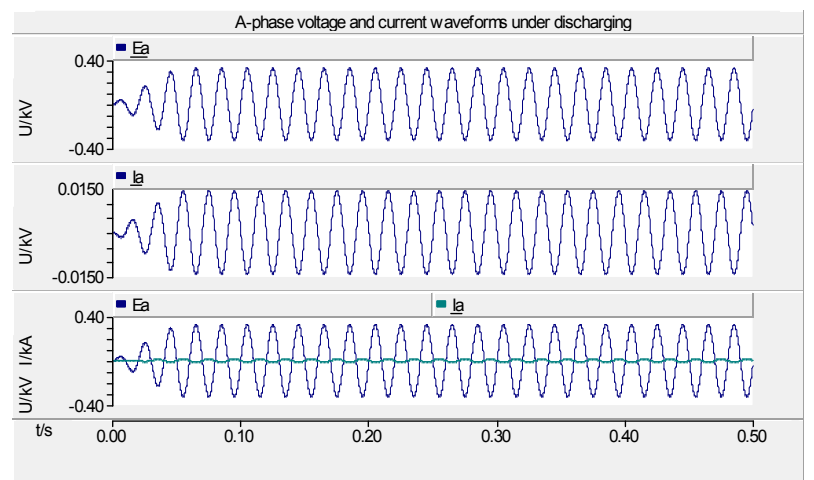

Figure 14. A-phase voltage and current waveforms under discharging.

Under the state of charging, spectrum analysis of the non-controlled rectifier AC side of the line voltage RMS $U a b, U a b 1=388.12 \mathrm{~V}, U a b 5=94.32 \mathrm{~V}, U a b 7=59.39$ $\mathrm{V}, U a b 11=34.55 \mathrm{~V}$, It can be seen that harmonic content is very high. Under the state of charging, spectrum analysis of the PWM rectifier AC side of the line voltage RMS Uab, $U a b 1=407.5 \mathrm{~V}, U a b 5=8.07 \mathrm{~V}$, $U a b 7=6.46 \mathrm{~V}, U a b 11=5.25 \mathrm{~V}$, It can be seen 5 th harmonic content is $2 \%$ using PWM control mode, 5th harmonic content is $24.3 \%$ by using non-controlled rectifier, harmonic content has been reduced by $22.3 \%$. Power quality has been improved. In Figure 14, the A-phase voltage and current waveforms in the discharged state of the electric vehicle, the system is running on the converter state, which can be seen by the waveform diagram of voltage and current of opposite phase.

\section{Conclusions}

Electric vehicle V2G charging and discharging device model studied in this paper, takes the control strategy based on the three phase voltage PWM converter and the DC/DC converter, which can achieve two-way energy interaction between the grid and electric vehicles, through simulation of PSCAD/EMTDC software. It is verified that a fully controlled system has obvious advantage than the traditional uncontrolled system, in views of the simulation result. The high power factor on the grid side and the stability of DC bus voltage can be achieved. The suppression of harmonic interference, sinusoidal current on the grid side and power quality are improved obviously. The realization of $\mathrm{V} 2 \mathrm{G}$ technology is more effective by using this method. On the basis of this study, the follow-up work is the modeling of Electric Vehicle charging station. It is the possible to make a further optimization on the control method.

\section{REFERENCES}

[1] Q. Zhong, "Research on Smart Grid Key Technology," Beijing: China Electric Power Press, Vol. 5, 2011, pp. 108-129.

[2] W. L. Zhang, B. Wu, W. F. Li, et al., "Discussion on Development Trend of Battery Electric Vehicles in China and Its Energy Supply Mode," Power System Technology, Vol. 33, No. 4, 2009, pp. 1-5.

[3] W. Kempton and S. Letendre, "Electric Vehicles as a New Power Source for Electric Utilities," Transportation Research Part D 23, 1997, pp. 157-175. doi:10.1016/S1361-9209(97)00001-1

[4] Kempton and Dhanju. "Electric Vehicles with V2G: Storage for Large-scale Wind Power," Windtech International, Vol. 2, No. 1, 2006, pp. 18-21.

[5] Y. X. Lu, X. M. Zhang and X. W. Pu, "Analysis of Electric Vehicles Charging Station Harmonics," Journal of electric power system and automation, Vol. 18, No. 3, 2006, pp. 51-54.

[6] M. Huang, S. F. Huang and J. C. Jiang. "Harmonic Study of Electric Vehicle Chargers," Beijing: Journal of Beijing Jiaotong University, Vol. 32, No. 5, 2008, pp. 85-88.

[7] X. Zhang and C. W. Zhang, "PWM Rectifier and Its Control," Beijing: China Machine Press, China Machine Press, Vol. 2, 2012, pp .49-65.

[8] Y. J. Chen and Y. P. Zhong, "Study on the Current Control for Voltage-Source PWM Rectifier Using Complex Vectors," Proceedings of the CSEE, Vol. 26, No. 2, 2006, pp. 141-148.

[9] G. K. Venayagamoorthy and P. Mitra, K. Corzine, et al., "Real-time Modeling of Distributed Plug-in Vehicles for V2G Transactions," IEEE Energy Conversion Congress and Exposition, 2009, pp. 3937-3941. 